\title{
A sustentabilidade nos projetos pedagógicos no ensino superior: um estudo sobre a engenharia de produção nas universidades públicas do Estado de São Paulo
}

Tiago Juliano

Ismail Barra Nova de Melo

Silvio César Moral Marques

Resumo: A Engenharia de Produção apresenta competências vinculadas à compreensão das relações entre o fenômeno produtivo e seus desdobramentos nos âmbitos econômicos, sociais e ambientais, atribuindo aos profissionais que atuam neste campo um papel relevante no desenvolvimento de alternativas que minimizem os impactos dos sistemas de produção, como exigência da sustentabilidade. O projeto pedagógico de um curso, por sua vez, é um processo de construção coletiva que revela a visão de mundo e de sociedade dos atores envolvidos com a instituição de ensino. Esta investigação é uma pesquisa documental que busca identificar quais dimensões do conceito de sustentabilidade são abordadas nas propostas pedagógicas das graduações em Engenharia de Produção de universidades públicas em São Paulo. A análise do conteúdo dos projetos da Escola Politécnica e da Escola de Engenharia de São Carlos, da Universidade de São Paulo; e da Universidade Federal de São Carlos indica uma concepção de sustentabilidade associada à preocupação com os impactos ambientais do sistema produtivo e que enfatiza o papel da empresa e da tecnologia, configurando as dimensões privilegiadas nas propostas destes cursos.

Palavras-chave: Sustentabilidade. Projeto pedagógico. Engenharia de Produção.

\section{Sustainability in pedagogical projects in higher education: a study concerning the production engineering of public universities in São Paulo State}

Abstract: The Production Engineering introduces skills related to the understanding of relations between the productive phenomenon and its consequences in the economic, social and environmental spheres, giving the professionals working in this field an important role in the development of alternatives that minimize the impacts of the production systems, as a requirement of sustainability. In the other hand, the pedagogical design of a course is a process of collective construction that reveals the worldview and vision of society of actors involved with an educational institution. This research is a documental study that seeks to identify which dimensions of sustainability are addressed in the educational proposals of undergraduate Production Engineering courses at the public universities in São Paulo state. The analysis of the educational project contents of the Polytechnic School and the School of Engineering of São Carlos (University of São Paulo) and the Federal University of São Carlos indicates the concept linked to concerns about the environmental impacts of the production system and the emphasis about the role of enterprises and technology for sustainability, setting the privileged dimensions inside the proposals of these courses.

Key words: Sustainability. Pedagogical project. Production Engineering. 
A sustentabilidade nos projetos pedagógicos no ensino superior: um estudo sobre a engenharia de produção nas universidades públicas do Estado de São Paulo

\section{Introdução}

O campo de estudo da Engenharia de Produção apresenta como uma das competências da área a compreensão das relações entre o sistema produtivo e seus desdobramentos no ambiente, nos aspectos ecológicos, sociais e econômicos, levando à incorporação de temas como produção mais limpa, ecoeficiência, responsabilidade social e gestão ambiental (SANTOS, 2003, 2008; FLEURY, 2008). Apesar da noção de finitude dos recursos naturais ser o ponto de partida de grande parte das propostas para o conceito de sustentabilidade, não existe consenso entre as diferentes perspectivas que buscam definir esta categoria (MATTOS; HERCOWITZ, 2011).

Em contrapartida, desde a definição de desenvolvimento sustentável como aquele que satisfaz as necessidades atuais, sem comprometer a capacidade de atender as necessidades das gerações futuras (CMMAD, 1988), esse discurso acerca do desenvolvimento tem, muitas vezes, sido empregado como sinônimo do conceito de sustentabilidade e o aproximado de três dimensões principais: ambiental, econômica e social. Por outro lado, essas dimensões clássicas não têm sido consideradas suficientes para abordar o caráter multifacetado do conceito de sustentabilidade: existem, ainda, dimensões imprescindíveis de ordem cultural, política e ética (LEFF, 2001; CAVALCANTI, 2012).

Nesse sentido, o projeto pedagógico de cursos de Engenharia de Produção pode apresentar elementos que indicam quais dimensões do conceito de sustentabilidade são priorizadas na formação e atuação destes profissionais. Para tanto, preconiza-se que projetos pedagógicos são processos coletivos que relevam os interesses da comunidade acadêmica e as atividades educativas necessárias para atingir os objetivos definidos, constituindo-se também espaços de diálogo que manifestam a visão de mundo e de sociedade da instituição de ensino e, portanto, superam a ideia reducionista de mero documento pragmático de um determinado curso (VEIGA, 2003; BARBOSA, 2012).

Esse estudo objetiva, portanto, identificar quais dimensões do conceito de sustentabilidade (ambientais, sociais, econômicas, culturais, políticas ou éticas) são abordadas nos projetos pedagógicos de cursos de graduação em Engenharia de Produção de universidades públicas no estado de São Paulo. Empreende-se uma análise do conteúdo e da finalidade das disciplinas, bem como dos objetivos, perfil, competências e habilidades profissionais, de atividades de pesquisa e extensão e das áreas de atuação e de conhecimento presentes nos projetos pedagógicos dos cursos investigados. 
Frente à diversidade de concepções associadas à sustentabilidade, as dimensões analisadas partem da proposta de uma revisão crítica do discurso de desenvolvimento sustentável, que enfatiza as dimensões ambientais, sociais e econômicas (CMMAD, 1988). Essa crítica amplia o conceito de sustentabilidade de forma a abordar relações de natureza cultural, política e ética (LEFF, 2001; CAVALCANTI, 2012).

A forma como essas dimensões são abordadas nas diferentes propostas do conceito de sustentabilidade, permitem aproxima-las de duas grandes correntes. Uma das linhas é representada por aspectos que priorizam a compatibilização do crescimento econômico contínuo com a racionalidade no uso de recursos, mantendo as estruturas produtivas que sustentam a hierarquização social. Outra linha contempla aspectos que enfatizam novas bases na apropriação social da natureza, indicando projetos civilizatórios, ou seja, estruturas e modelos sociais, cujo objetivo maior é superar propostas de caráter reformista que acabam por manter as polaridades sociais (DIAS, 2008).

\section{$2 \mathrm{O}$ significado do projeto pedagógico}

O projeto político pedagógico encerra um sentido de processo emancipatório mais abrangente do que sua concepção como documento regulatório na condição de produto final (VEIGA, 2003). Pode ser definido como espaço de discurso, debate e disputa de poder entre interesses diferentes de uma instituição de ensino, transcendendo o âmbito estrutural para integrar o contexto histórico e social no qual é concebido (BARBOSA, 2012; SACRISTÁN, 2000).

É um processo político porque assume a instituição de ensino como uma organização social que objetiva formar um cidadão para um determinado modelo de sociedade. É um processo pedagógico porque busca definir ações de educação para mudar certa realidade (BARBOSA, 2012; CAÇÃO, 2010; VASCONCELLOS, 2012; VEIGA, 2003).

A construção do projeto pedagógico não prescinde de seu caráter coletivo. Silva (2001) o define como um documento teórico-prático elaborado por diferentes sujeitos da instituição de ensino e que integra premissas filosóficas e políticas, valores humanísticos e o que considera como funções sociais e históricas de sua responsabilidade, revelando quem é a comunidade envolvida e permitindo avaliar democraticamente o trabalho da instituição.

Além da participação, outra dimensão importante para a construção do projeto pedagógico é a autonomia da Instituição de Ensino. A instituição autônoma não pode depender da 
A sustentabilidade nos projetos pedagógicos no ensino superior: um estudo sobre a engenharia de produção nas universidades públicas do Estado de São Paulo

centralidade na proposição da política educativa, mas ao contrário deve poder executar e avaliar sua própria ação pedagógica (VEIGA, 2011).

\section{As dimensões da sustentabilidade}

O conceito de sustentabilidade tem construído um campo de debate entre diferentes linhas de pensamento, no qual se confrontam concepções, ideias, valores e ideologias tão distintos quanto as formas de pensar de quem os propõem. No entanto, é a percepção de finitude dos recursos e a tentativa de construir modelos que permitam conciliar a linearidade do sistema econômico e produtivo aos limites do sistema ecológico que parecem ser o ponto de partida comum para a construção do conceito de sustentabilidade (GADOTTI, 2008; MATTOS; HERCOWITZ, 2011; NASCIMENTO, 2012).

Dias (2008) sublinha a falta de consenso na definição e contrapõe duas grandes correntes, sendo que uma prioriza o crescimento econômico contínuo, com base no uso racional de recursos naturais e de tecnologias menos poluentes, enquanto outra questiona as próprias bases da organização produtiva da sociedade, discutindo as nuances de um projeto social e político que visa superar propostas reformistas de desenvolvimento e busca um modelo de sociedade diferente do atual, no qual a produção seja condizente com os limites do meio biofísico e que considere necessidades humanas não restritas à riqueza material:

[...] Ou seja, para alguns se trata somente de compatibilizar o meio ambiente com um crescimento econômico contínuo, mantendo as condições que produzem e reproduzem as relações de exploração, hierarquização e dominação que permitem a apropriação da capacidade produtiva social por alguns homens. Para outros, implica novas bases, nas quais se sustenta a civilização, através da construção de uma nova racionalidade, uma racionalidade ambiental que coloque como sentido e fim da organização social produtiva o bem-estar material do ser humano (nível de vida) e seu desenvolvimento espiritual (qualidade de vida) (DIAS, 2008, p. 32).

A primeira dessas correntes é a mais facilmente empregada e encontrada nas discussões sobre sustentabilidade e pode-se dizer que se desdobra tanto no âmbito do processo econômico como um todo, quanto no da organização privada. Uma das expressões mais comuns desta linha é a do desenvolvimento sustentável (CMMAD, 1988), no qual a dimensão ambiental se refere à minimização da depleção de recursos naturais; a econômica à manutenção do crescimento produtivo através do progresso tecnológico contínuo; e a social à promoção da inclusão social por meio da redução da pobreza (ABRAMOVAY, 2012; CAVALCANTI, 2012; SACHS, 2012). 
A ideia de economia verde emerge deste conceito chave e, ainda que procure inovar propondo investimentos em setores produtivos menos poluentes para configurar um processo de descarbonização e desmaterialização da economia, acaba por ser considerada uma reiteração do que o conceito de desenvolvimento sustentável já propunha (ALMEIDA, 2012; CECHIN; PACINI, 2012; ROMEIRO, 2012).

As vertentes da economia do meio ambiente também procuram se inscrever como paradigmas da sustentabilidade. Com efeito, a economia ambiental aponta a sustentabilidade como um exclusivo problema de alocação temporal dos recursos e aborda os limites ecológicos como relativos e superáveis devido ao permanente avanço científico que permite reduzir o uso de insumos e a geração de rejeitos (MATTOS; HERCOWITZ, 2011; ROMEIRO, 2012). A economia ecológica, por sua vez, é a outra vertente que considera o processo econômico um subsistema do sistema ecológico, defendendo limites absolutos ao crescimento, posto que embora a tecnologia possa diminuir os impactos naturais, existem limites entrópicos ao processo produtivo (ANDRADE; ROMEIRO, 2009; MATTOS; HERCOWITZ, 2011; ROMEIRO, 2012).

Dias (2008) sinaliza que a compatibilização entre crescimento econômico e conservação dos recursos naturais também está presente no âmbito da organização privada, na qual a gestão ambiental pode ser definida como a condução gerencial da empresa que procura minimizar impactos do processo produtivo, observando a capacidade de carga do ambiente. A gestão ambiental observa, ainda, as expectativas dos diferentes públicos envolvidos com a empresa, sendo, por vezes, considerada um componente da gestão da qualidade (SELIG; CAMPOS; LERIPIO, 2008).

Além disso, é importante frisar que a auto sustentação, a viabilidade econômica e o retorno aos investimentos (QUELHAS; ALLEDI FILHO; MEIRIÑO, 2008), bem como as inovações gerenciais e tecnológicas que geram maior valor à organização por meio do menor uso de recursos e de poluição, traduzidas frequentemente nos conceitos de responsabilidade social, ecoeficiência e produção mais limpa, correspondem à ideia que as empresas usualmente associam ao conceito de sustentabilidade (DIAS, 2008).

A segunda grande corrente, por outro lado, denota à sustentabilidade um significado mais abrangente que as concepções descritas acima. A crença na eficiência tecnológica e a redução da pobreza, bases do conceito de desenvolvimento sustentável, não significam necessariamente a redução das desigualdades sociais (ABRAMOVAY, 2012), assim como nem tudo pode ser expresso na métrica monetária, como propõe a economia verde (ALMEIDA, 2012; CECHIN; PACINI, 2012). 
A sustentabilidade nos projetos pedagógicos no ensino superior: um estudo sobre a engenharia de produção nas universidades públicas do Estado de São Paulo

Desenvolvimento não se resume às inovações de ordem técnica para que a sociedade possa produzir de forma mais eficiente, passando a incorporar relações de apropriação de diferentes direitos humanos, a partir de uma pluralidade de definições das necessidades humanas que não se limitam ao modelo de crescimento econômico dominante (SACHS, 2002). Não se trata de negar a ideia de desenvolvimento, mas de reconhecer que o discurso de desenvolvimento sustentável tem buscado compatibilizar um crescimento econômico ilimitado com um meio físico essencialmente limitado, visando atender uma demanda não necessariamente condizente com as necessidades reais da sociedade (LEFF, 2001).

Nessa perspectiva, as dimensões clássicas do conceito de sustentabilidade que emergem do discurso de desenvolvimento sustentável (ambiental, social e econômica) (CMMAD, 1988) são complementadas por outras dimensões mais críticas: o conceito de sustentabilidade não pode prescindir da dimensão cultural, correspondente à mudança de valores da sociedade; da dimensão política, cujas estruturas de poder e processos de decisão definem o padrão de produção e consumo dominante; e da dimensão ética, que considera a heterogeneidade de visões de mundo e grupos sociais envolvidos nas diferentes formas de apropriação social dos recursos naturais (LEFF, 2001; CAVALCANTI, 2012).

\section{Engenharia de Produção na universidade pública de São Paulo}

Esta pesquisa tem como objetivo identificar as dimensões da sustentabilidade presentes nos projetos pedagógicos dos cursos de graduação em Engenharia de Produção de universidades públicas do estado de São Paulo. Como critério de seleção, foram elencados os cursos de graduação ofertados por Instituições que contemplam programas de mestrado e doutorado, pressupondo que as atividades de pós-graduação são indicativos de maturidade institucional e de consolidação da proposta pedagógica dos cursos. No Brasil, vinte e dois programas de pósgraduação em Engenharia de Produção oferecem concomitantemente cursos de mestrado e doutorado, sendo três destes programas vinculados a instituições públicas de São Paulo (CAPES, 2013).

A partir deste recorte, a amostra do presente estudo contempla os cursos de Engenharia de Produção da Escola Politécnica e da Escola de Engenharia de São Carlos (EESC), ambos da Universidade de São Paulo, e o curso da Universidade Federal de São Carlos, campus São Carlos. O curso de Engenharia de Produção da Escola Politécnica foi o primeiro a ser criado no país em 1958, como opção do curso de Engenharia Mecânica até 1970, quando deixa de ser uma modalidade para se constituir em carreira autônoma. O curso da EESC, por sua 
vez, teve funcionamento autorizado a partir de 1971 e possui ênfase na grande área da Mecânica. Por fim, o curso da Universidade Federal de São Carlos passou a apresentar proposta para formação em Engenharia de Produção plena a partir de 2005, quando foi promovida a fusão dos antigos cursos de Engenharia de Produção Química e de Materiais, criados em 1976, e da opção Agroindustrial, criada em 1993.

Este estudo emprega o método de pesquisa documental, analisando os projetos e propostas pedagógicos dos cursos de graduação selecionados. Foram estudados os objetivos, conteúdos e indicações bibliográficas de cento e noventa e sete disciplinas obrigatórias previstas na grade curricular dos cursos. Como critério de análise, buscou-se identificar nas disciplinas dos cursos de graduação a abordagem, direta ou indireta, de uma ou mais dimensões do conceito de sustentabilidade, conforme descritas anteriormente. Por abordagem direta, considerou-se a presença e/ou definição do conceito de sustentabilidade ou do qualificativo correspondente (sustentável) nos objetivos, conteúdos ou referências das disciplinas; enquanto por abordagem indireta, compreendeu-se a expressão de pelo menos uma das dimensões do conceito de sustentabilidade, ainda que este conceito não tenha sido citado ou definido explicitamente na descrição da disciplina.

Também foram investigados o perfil e as aptidões profissionais, as competências e as habilidades, as atividades de pesquisa e extensão, as áreas de atuação e de conhecimento destes cursos. As atividades de pesquisa e extensão foram analisadas a partir da definição dos objetivos de vinte e sete grupos de estudo vinculados aos cursos de Engenharia de Produção das Instituições de Ensino, enquanto os demais elementos foram estudados a partir das propostas descritas nos projetos pedagógicos dos três cursos. Em ambos os casos, foram empregados os mesmos critérios utilizados na análise das disciplinas: abordagem, direta ou indireta, de uma ou mais dimensões do conceito de sustentabilidade nos documentos dos cursos de Engenharia de Produção das instituições elencadas.

\section{O papel da Engenharia de Produção para a sustentabilidade}

A Engenharia de Produção pode ser definida como a área responsável pelo projeto, pelo aperfeiçoamento e pela implantação de sistemas que integram pessoas, materiais, informações, equipamentos e energia para a produção de bens e serviços, de maneira econômica e com base em preceitos éticos e culturais (SANTOS, 2008).

No Brasil, os cursos de Engenharia de Produção definiram, em um primeiro estágio, conteúdos de conhecimento e cargas horárias mínimas como condições suficientes para a 
A sustentabilidade nos projetos pedagógicos no ensino superior: um estudo sobre a engenharia de produção nas universidades públicas do Estado de São Paulo

formação profissional. Os resultados desse processo de regulamentação dos cursos de Engenharia de Produção foram a especialização e o isolamento dos docentes em disciplinas específicas, com prejuízo à interdisciplinaridade dos conteúdos e um distanciamento entre os projetos pedagógicos e a prática de atividades educativas. Em um estágio subsequente, sobretudo, a partir da instituição das Diretrizes Curriculares (BRASIL, 2002), o estabelecimento de competências e habilidades como bases da graduação legou uma maior flexibilidade aos currículos dos cursos de Engenharia de Produção (SANTOS, 2003, 2008; VIEIRA JUNIOR; FARIA, 2008).

O perfil pensado na formação do engenheiro de produção e os objetivos dos cursos apresentam uma influência cada vez maior de questões de ordem social e ambiental. Fleury (2008) defende que os problemas e regulações ambientais e sociais colocam aos profissionais desta área desafios relacionados à produção limpa e à responsabilidade social, tornando sua atuação junto à sociedade relevante para a sustentabilidade.

Dentre as competências profissionais previstas nas Diretrizes Curriculares, Santos (2003) elenca que cabe ao engenheiro de produção "avaliar o impacto das atividades da engenharia no contexto social e ambiental" (p. 28). Estas competências são complementadas pela Associação Brasileira de Engenharia de Produção (ABEPRO), que aponta o objetivo de formar um profissional que compreenda "[...] a inter-relação dos sistemas de produção com o meio ambiente, tanto no que se refere à utilização de recursos escassos quanto à disposição final de resíduos e rejeitos, atentando para a exigência de sustentabilidade” (p. 28).

Na maior parte das Instituições de Ensino, apesar de a Engenharia de Produção formar profissionais que atuam em setores que podem ter um elevado impacto ambiental, bem como apesar do fato de a grade curricular desses cursos contemplar questões sociais, ambientais econômicas, “[...] as disciplinas que abordam a questão ambiental, tratam especificamente da "produção limpa" a qual, em geral, é tratada em seus últimos semestres" (HEIN; KROENKE; ROCHA, 2009, p. 70).

Em contrapartida, Fuks (2012) ressalta que as principais ferramentas da gestão ambiental, como ecoeficiência, produção mais limpa e responsabilidade social corporativa, não são sinônimos de sustentabilidade, porque encerram a ideia que estas ferramentas apenas se justificam em função dos retornos financeiros à firma. Não se trata de propor que estas práticas não devam ser implantadas pela empresa, mas de reconhecer que elas são insuficientes para serem tomadas como conceito de sustentabilidade (FUKS, 2012).

Portanto, considerando o papel da área de Engenharia de Produção no campo da sustentabilidade, cabe entender de que maneira seus cursos de graduação relacionam o conceito 
de sustentabilidade com as diretrizes dos projetos pedagógicos. Devido ao enfoque técnico, este campo de estudo pode privilegiar as dimensões do conceito de sustentabilidade que buscam promover o crescimento produtivo mais eficiente e menos impactante, sobretudo, no que concerne às dimensões econômicas e ambientais; e reservar um menor espaço no currículo para discussões mais abrangentes sobre o conceito de sustentabilidade, que preconizam a abordagem de outras dimensões, como apontado previamente.

\section{Os projetos pedagógicos analisados: uma leitura acerca do conteúdo}

A matriz curricular dos cursos analisados segue a orientação das Diretrizes Curriculares para Engenharia, estando organizada com base em módulos que contemplam conteúdos básicos, profissionalizantes e específicos. É uma característica comum destes cursos apresentar disciplinas relacionadas às ciências ambientais e sociais no módulo básico do currículo, ao passo que a gestão ambiental se insere no módulo de conteúdos específicos, como parte dos conhecimentos gerenciais a serem desenvolvidos pelo estudante.

A identificação das dimensões do conceito de sustentabilidade no ementário dos cursos selecionados nesta pesquisa não é regular. Os cursos de Engenharia de Produção da Escola Politécnica e da EESC apresentam uma quantidade maior de disciplinas que abordam alguma das dimensões do conceito de sustentabilidade, ainda que quando comparada com a carga horária total e com o número total de disciplinas do curso esta representatividade seja pequena. (Tabela 1).

\section{Tabela 1 - Representatividade das disciplinas nas quais foi identificada a abordagem de uma ou mais dimensões da sustentabilidade}

\begin{tabular}{cccc}
\hline & Escola Politécnica & EESC & UFSCar \\
\hline $\begin{array}{c}\text { Número de disciplinas identifica- } \\
\text { das }\end{array}$ & 8 & 6 & 2 \\
\hline $\begin{array}{c}\% \text { em relação ao total de discipli- } \\
\text { nas do curso }\end{array}$ & $12,12 \%$ & $10 \%$ & $2,8 \%$ \\
\hline $\begin{array}{c}\% \text { em relação à carga horária } \\
\text { ideal do curso }\end{array}$ & $12,8 \%$ & $10,38 \%$ & $3,05 \%$ \\
\hline
\end{tabular}

Fonte: elaboração própria, a partir dos projetos pedagógicos da Escola Politécnica (USP), EESC (USP) e UFSCar.

As disciplinas nas quais foram identificadas dimensões do conceito de sustentabilidade não estão presentes em todos os anos da graduação e possuem uma distribuição heterogênea ao longo dos semestres (Quadro 1). Entretanto, verifica-se uma tendência de concentração 
A sustentabilidade nos projetos pedagógicos no ensino superior: um estudo sobre a engenharia de produção nas universidades públicas do Estado de São Paulo

destas disciplinas entre o quinto e oitavo semestres dos cursos, quando os conteúdos específicos são ministrados.

\section{Quadro 1 - Distribuição das disciplinas nas quais foi identificada a abordagem de uma ou mais dimensões da sustentabilidade ao longo dos semestres}

\begin{tabular}{|c|c|c|c|c|c|c|c|c|c|c|}
\hline & 1SM & $2 S M$ & 3SM & $4 S M$ & $5 S M$ & $6 \mathrm{SM}$ & 7SM & 8SM & 9SM & $10 \mathrm{SM}$ \\
\hline Escola Politécnica & $1 \mathrm{D}$ & & & $1 \mathrm{D}$ & $1 \mathrm{D}$ & $2 \mathrm{D}$ & $1 \mathrm{D}$ & $2 \mathrm{D}$ & & \\
\hline EESC & $1 \mathrm{D}$ & & & $1 \mathrm{D}$ & & $1 \mathrm{D}$ & $2 \mathrm{D}$ & $1 \mathrm{D}$ & & \\
\hline UFSCar & & & & $1 \mathrm{D}$ & $1 \mathrm{D}$ & & & & & \\
\hline
\end{tabular}

Legenda: SM - semestre; 1D - 01 disciplinas; 2D - 02 disciplinas.

Fonte: elaboração própria, a partir dos projetos pedagógicos da Escola Politécnica (USP), EESC (USP) e UFSCar.

No programa dessas disciplinas, predomina uma abordagem indireta, ou seja, pelo menos uma das dimensões do conceito de sustentabilidade é abordada, sem citá-lo ou definilo. É o caso da disciplina 'Introdução à Engenharia', do primeiro semestre da Escola Politécnica, que elenca que dentre as habilidades e atitudes do engenheiro de produção estão "preocupar-se com aspectos econômicos, sociais e ambientais" (USP, 2013). Relacionado ao predomínio de uma abordagem indireta da sustentabilidade, as disciplinas priorizam uma preocupação com os impactos, efeitos e resultados das ações antrópicas, bem como acerca dos requisitos ambientais para sistemas produtivos, projetos e produtos de engenharia.

Por outro lado, quando o conceito de sustentabilidade é abordado diretamente, seu emprego não está acompanhado por uma definição clara. Com efeito, apenas a disciplina 'Produção e Sustentabilidade', do oitavo semestre da Escola Politécnica, delimita o conceito de sustentabilidade adotado. Nessa disciplina, "sustentabilidade é entendida a partir do triple bottom line, ou seja, a sustentabilidade técnico-econômica trabalhada conjuntamente com a sustentabilidade ambiental e a sustentabilidade social" (USP, 2013).

De forma geral, uma abordagem direta da sustentabilidade se encontra vinculada às disciplinas que debatem as relações entre engenharia, sociedade e ciências humanas, bem como entre engenharia e ciências ambientais. O Quadro 2 elenca as disciplinas nas quais se identificou pelo menos uma das dimensões do conceito de sustentabilidade, conforme a descrição dos objetivos, conteúdos ou referências dessas disciplinas, abordadas tanto de forma direta quanto indireta. 
Quadro 2 - Dimensões do conceito de sustentabilidade identificadas em disciplinas de graduação em Engenharia de Produção

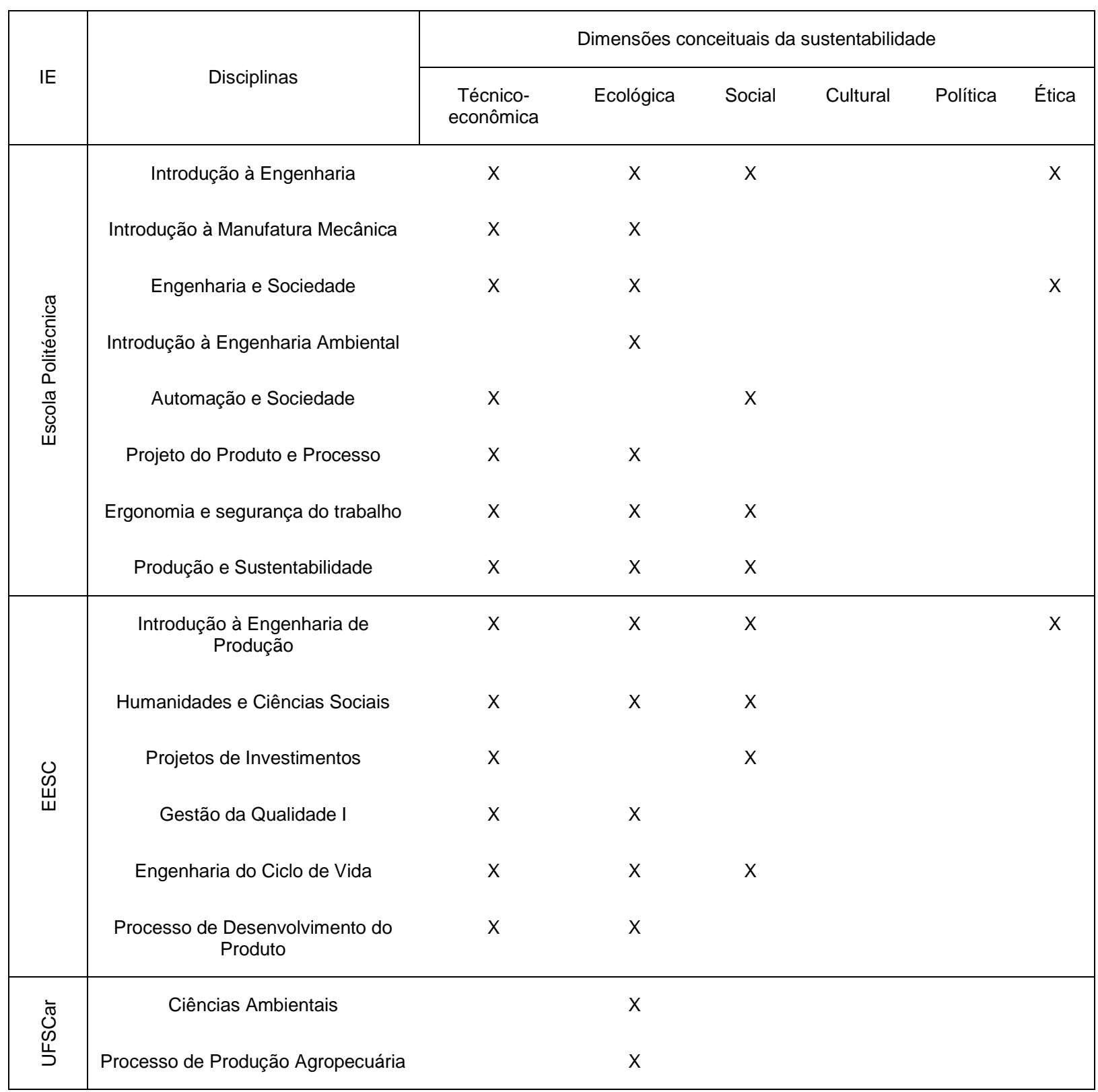

Legenda: $\mathrm{x}$ - indica a abordagem de uma dimensão do conceito de sustentabilidade pela disciplina. Fonte: elaboração própria, a partir dos projetos pedagógicos da Escola Politécnica (USP), EESC (USP) e UFSCar.

A gestão da qualidade é conteúdo de todos os cursos investigados, sendo a gestão ambiental apresentada como um dos componentes dessa disciplina. Existe ênfase no controle da poluição, contaminação e geração de resíduos e os temas mais debatidos são o de responsabilidade social corporativa, produção mais limpa, cadeia produtiva verde, gestão do ciclo de vida, certificação e auditoria de requisitos ambientais, ecoeficiência e ecodesign (Quadro 3). 
A sustentabilidade nos projetos pedagógicos no ensino superior: um estudo sobre a engenharia de produção nas universidades públicas do Estado de São Paulo

Quadro 3 - Temas mais frequentes associados ao conceito de
sustentabilidade em disciplinas de Engenharia de Produção

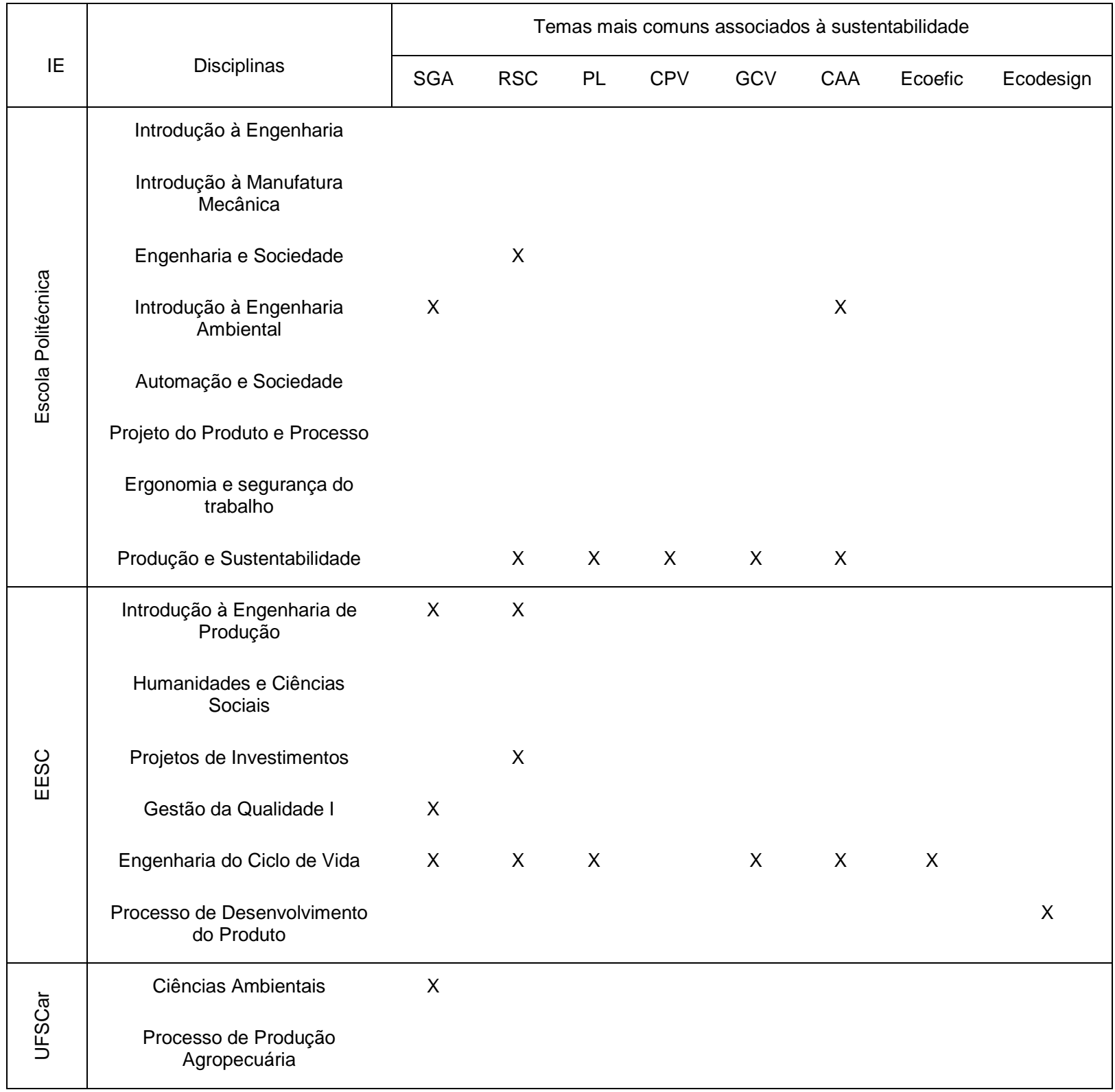

Legenda: $\mathrm{x}$ - indica a abordagem de uma dimensão do conceito de sustentabilidade pela disciplina; SGA Sistema de Gestão Ambiental; RSC - Responsabilidade Social Corporativa; PL - Produção Mas Limpa; CPV Cadeia Produtiva Verde; GCV - Gestão do Ciclo de Vida; CAA - Certificação e Auditoria Ambiental; Ecoefic Ecoeficiência.

Fonte: elaboração própria, a partir dos projetos pedagógicos da Escola Politécnica (USP), EESC (USP) e UFSCar.

Desta maneira, embora o conceito de sustentabilidade seja empregado de formas diferentes tanto nas disciplinas de um mesmo projeto pedagógico (Quadro 2), quanto nas diferentes Instituições de Ensino (Quadro 3), é relevante sinalizar que prevalece a concepção que 
associa a sustentabilidade à noção de impacto dos sistemas produtivos, revelando o recorte conceitual priorizado no projeto pedagógico dos cursos elencados na pesquisa.

Embora o perfil descrito nas propostas pedagógicas dos cursos de Engenharia de Produção apresente um viés técnico, identificam-se em todas as Instituições de Ensino estudadas elementos que contemplam a preocupação com uma formação humanística. Com efeito, o perfil profissional almejado pela Escola Politécnica prevê dentre as aptidões a formação de consciência do engenheiro sobre sua condição de agente de evolução econômica e social, devendo ter uma visão mais abrangente do que o domínio das habilidades técnicas. A EESC e a Universidade Federal de São Carlos compartilham, em essência, a descrição do perfil profissional, abrangendo uma sólida formação científica e tecnológica para organizar e resolver problemas no âmbito do sistema produtivo e levando em consideração aspectos humanos, políticos, econômicos, sociais, ambientais e culturais da sociedade.

As competências e habilidades previstas nos projetos pedagógicos, por sua vez, vinculam o conceito de sustentabilidade ao impacto das atividades produtivas, sobretudo, das industriais. Entende-se que o engenheiro de produção deve ser capaz de implantar produtos e processos que considerem limites produtivos no que se refere ao uso de recursos escassos e à disposição de resíduos (UFSCAR, 2009), bem como apresentar como competência a análise dos desdobramentos ambientais e sociais da produção, desenvolvendo habilidades de responsabilidade social e ambiental (USP, 2001).

Enquanto é identificada certa homogeneidade na definição do perfil, das competências e das habilidades profissionais nos cursos elencados, as propostas pedagógicas apresentam diferentes abordagens quanto às áreas de conhecimento e de atuação. A Escola Politécnica define que foi reservado espaço para as áreas de ciências humanas e ambientais na estrutura curricular da engenharia, com o objetivo de conceber uma formação mais humanística e não puramente técnica. O curso da Universidade Federal de São Carlos, por sua vez, busca formar profissionais para atuar nas mais diversas atividades gerenciais, inclusive na alta direção empresarial, por meio de conhecimentos de áreas mais clássicas da engenharia e de novos campos de gestão empresarial. Por fim, a EESC sinaliza que o curso reúne conhecimentos de diferentes áreas do saber, como matemática, física, engenharia, economia, sociologia, psicologia e administração, elencando as grandes áreas da Engenharia de Produção, dentre as quais destaca o papel da gestão ambiental na abordagem da sustentabilidade.

$\mathrm{Na}$ análise das atividades de pesquisa e extensão, foram considerados os objetivos e linhas de pesquisa dos grupos de estudo dos programas de Engenharia de Produção das três instituições investigadas, que juntas somam vinte e sete grupos. Foram identificados quatro 
A sustentabilidade nos projetos pedagógicos no ensino superior: um estudo sobre a engenharia de produção nas universidades públicas do Estado de São Paulo

grupos que abordam dimensões do conceito da sustentabilidade na descrição de suas atividades institucionais (Quadro 4).

Na Escola Politécnica, o grupo de estudos "Gestão de Operações e Logística” possui uma linha de pesquisa que busca integrar o sistema de gestão ambiental com o padrão de produção e desenvolver sistemas de logística para a produção sustentável. Na mesma instituição, o grupo de estudos "Qualidade e Engenharia do Produto" aborda a gestão da qualidade sob a perspectiva da melhoria de processos, bem como da normatização de sistemas como responsabilidade social e ambiental.

\section{Quadro 4 - Representatividade dos grupos de estudo, linhas de pesquisa e disciplinas de pós graduação das instituições estudadas, nos quais se identificou a abordagem de uma ou mais dimensões da sustentabilidade}

\begin{tabular}{ccccc} 
& & Escola Politécnica & EESC & UFSCar \\
\cline { 2 - 4 } Grupos de Estudo & Total & 5 & 10 & 12 \\
\cline { 2 - 5 } & $\begin{array}{c}\text { Com referências à } \\
\text { sustentabilidade }\end{array}$ & 2 & 2 & 0 \\
\hline Linhas de Pesquisa & Total & 14 & 8 & 0 \\
\cline { 2 - 5 } & $\begin{array}{c}\text { Com referências à } \\
\text { sustentabilidade }\end{array}$ & 2 & 3 & 47 \\
\hline Disciplinas & Total & 42 & 53 & 1 \\
\cline { 2 - 5 } & $\begin{array}{c}\text { Com referências à } \\
\text { sustentabilidade }\end{array}$ & 5 & 5 & 6 \\
\hline
\end{tabular}

Fonte: elaboração própria, a partir dos projetos pedagógicos da Escola Politécnica (USP), EESC (USP) e UFSCar.

O grupo de estudos "Engenharia e Gestão do Ciclo de Vida dos Produtos" da EESC desenvolve pesquisas sobre a temática da sustentabilidade com foco no produto (ecodesign, avaliação do ciclo de vida, estratégia de fim de vida dos produtos), no processo (produção mais limpa, prevenção à poluição e ecoeficiência), na gestão (certificação ambiental, rotulagem ambiental, indicadores de desempenho, gestão socioambiental, estratégias em sustentabilidade) e na tecnologia (tecnologias limpas e sistemas de informação). A EESC também possui vinculada à Engenharia de Produção o grupo de estudos "Engenharia Integrada", o qual empreende pesquisas sobre o gerenciamento dos processos de desenvolvimento de produtos, abordando a linha de pesquisa sobre ecodesign.

Enquanto na Escola Politécnica os grupos de estudo se orientam por uma aproximação do conceito de sustentabilidade ao conceito de gestão ambiental, os grupos de estudo na EESC que abordam o conceito de sustentabilidade enfatizam o ciclo de vida dos produtos. Existe, assim, uma correspondência entre as dimensões do conceito de sustentabilidade abor- 
dadas tanto na graduação quanto na pós-graduação, ainda que a representatividade proporcional das disciplinas que contemplam discussões sobre sustentabilidade seja maior na pósgraduação (Quadro 4). Portanto, os grupos de estudo são importantes ferramentas de integração entre as atividades dos diferentes níveis do ensino superior e podem contribuir para ampliar o debate sobre a sustentabilidade na área de Engenharia de Produção.

\section{A sustentabilidade nos projetos pedagógicos}

A concepção dos projetos pedagógicos dos cursos de Engenharia de Produção abordados pela pesquisa segue tanto as orientações do sistema educacional e profissional desta área, quanto às exigências do mercado de trabalho que determinam o perfil profissional desejado para o egresso (VIEIRA JUNIOR; FARIA, 2008). Este campo de atuação adota uma concepção de racionalidade econômica aplicada ao processo de produção (FLEURY, 2008) e não deixa de incorporar elementos que denotam uma preocupação com o tema da sustentabilidade, priorizando o planejamento na utilização eficiente dos recursos do sistema produtivo em diferentes setores econômicos, o destino dos resíduos deste sistema e a implantação de ferramentas de gestão ambiental e responsabilidade social (ABEPRO, 2013).

Desta maneira, a sustentabilidade emerge como exigência do processo de produção de bens e serviços, a partir da perspectiva de escassez de recursos que sustentam o sistema produtivo e de alocação adequada dos resíduos gerados. A análise das dimensões do conceito de sustentabilidade encontradas nas propostas pedagógicas dos cursos investigados permite apontar que a preocupação com os impactos e requisitos ambientais de projetos e produtos de engenharia é o centro das discussões realizadas pelas disciplinas no que concerne à sustentabilidade.

Há preferência pela noção de sustentabilidade no lugar da referência ao desenvolvimento sustentável, embora a ideia dominante esteja fortemente atrelada ao segundo termo. Esta constatação se sustenta com base na ênfase dada pelos projetos pedagógicos à eficiência tecnológica, visando superar a contradição entre o crescimento ao longo prazo e as limitações ecossistêmicas e deixando em segundo plano a reflexão acerca das desigualdades sociais (ABRAMOVAY, 2012) e do acesso universal aos direitos humanos, que definem de forma mais elementar o conceito de desenvolvimento (SACHS, 2002).

Nas propostas pedagógicas analisadas, prioriza-se o desenvolvimento da capacidade profissional para o desenvolvimento de novas tecnologias e o papel da empresa para a sustentabilidade, aproximando o conceito de sustentabilidade à concepção de gestão ambiental e 
A sustentabilidade nos projetos pedagógicos no ensino superior: um estudo sobre a engenharia de produção nas universidades públicas do Estado de São Paulo

responsabilidade social corporativa. No âmbito empresarial, a atuação profissional em relação à sustentabilidade abrange a otimização do ciclo produtivo através do uso de menos recursos e geração de menos resíduos, bem como de sistemas de certificação que levem maior credibilidade às ações empresarias (SELIG; CAMPOS; LERÍPIO, 2008).

É identificada uma orientação dos cursos de Engenharia de Produção para discutir a mudança de paradigmas produtivos, dando margem à incorporação de temas relacionados à produção flexível que centralizam uma preocupação com a cadeia produtiva e o ciclo de vida dos produtos. Contudo, para Dias (2008), o discurso empresarial tem promovido uma ressignificação da sustentabilidade que lega ao conceito uma interpretação mais relacionada à gestão eficiente do que à mobilização do empresariado quanto ao papel das empresas como agentes de transformação social. Fuks (2012) complementa esta visão, apontando que estas ideias só fazem sentido enquanto geram valor à empresa e que a eficiência tecnológica não encerra a problemática socioambiental: por mais eficiente que seja, o crescimento da produção continua pressionando entropicamente o sistema natural.

Ao enfatizar o papel das empresas, as propostas pedagógicas dos cursos analisados privilegiam dimensões econômicas, sociais e ambientais do conceito de sustentabilidade, não esclarecendo sua diferença para o discurso do desenvolvimento sustentável. O uso generalizado destes termos esvazia o potencial crítico do conceito de sustentabilidade, que consiste em apontar as contradições entre um crescimento econômico contínuo e os limites do ambiente (LEFF, 2001), além de estar associado à menor importância atribuída ao contexto sócio político em que é concebido e pela relevância cada vez maior denotada às inovações tecnológicas (CAVALCANTI, 2012).

Não se encontra nos projetos pedagógicos analisados espaço significativo para o debate de conceitos de sustentabilidade que questionem justamente a sustentação dos modelos de produção da sociedade, reduzindo a potencial crítica em relação à perspectiva reformista de desenvolvimento, que prevalece dominante (DIAS, 2008). O enfoque técnico dos cursos e a importância denotada ao domínio e ao progresso de tecnologias menos poluentes podem estar relacionados a esta inferência.

Para Leff (2001), a sustentabilidade na condição de discurso que busca justificar o crescimento e a manutenção do padrão de produção e consumo promove uma despolitização do conceito. Pode ignorar o problema dos limites e das polaridades sociais não enfrentadas pela eficiência tecnológica (ABRAMOVAY, 2012) e manter os valores que afastam a concepção de um projeto civilizatório baseado em uma racionalidade centrada no homem e não nas necessidades do mercado (LEFF, 2001; DIAS, 2008; GADOTTI, 2008). 


\section{Considerações Finais}

A inserção do conceito de sustentabilidade nos projetos pedagógicos permite compreendê-los como processos reveladores da visão de mundo e de sociedade que uma instituição de ensino carrega, indicando as interpretações sobre sustentabilidade que o profissional terá contato ao longo de sua formação. Admite-se, assim, que o projeto pedagógico encontra sentido em sua função emancipatória, comprometendo-se em superar a formação técnica para contemplar uma formação cidadã. A sustentabilidade, por sua vez, enquanto campo de debate que dá margem a diferentes interpretações e aplicações, potencializa uma ressignificação dos valores do sistema educativo.

Frente à falta de consenso acerca do conceito, adotou-se a proposta de Dias (2008), agrupando-se as diferentes abordagens sobre sustentabilidade em duas grandes correntes: uma que busca conciliar o crescimento econômico com a racionalidade no uso de recursos por meio do avanço técnico e outra que está centrada na reflexão sobre o processo de apropriação da natureza que leve à minimização das polaridades sociais e ao bem-estar humano. $\mathrm{O}$ campo da Engenharia de Produção, por sua vez, apresenta a proposta de agregar à formação técnica característica da área, um desenvolvimento humanístico que abrange conhecimentos gerenciais mais amplos e permitem ao profissional uma visão holística do sistema produtivo e, consequentemente, das implicações sociais e ambientais do fenômeno da produção, atentando-se para a exigência da sustentabilidade.

O conceito de sustentabilidade está inserido nos projetos pedagógicos dos cursos de Engenharia de Produção de universidades públicas do estado de São Paulo corroborando a primeira corrente conceitual discutida acima, associando-se à preocupação com os impactos e requisitos ambientais de projetos, processos e produtos de engenharia, bem como ao papel da empresa. Essa constatação indica que, ao ser internalizada nas propostas dos cursos analisados, a concepção de sustentabilidade pode ser considerada o equivalente à gestão ambiental ou responsabilidade social, reduzindo o espaço de outras dimensões mais amplas do conceito de sustentabilidade, como as de natureza política, cultural e ética.

A relação entre o uso racional dos recursos naturais e a atuação dos agentes econômicos insere nos programas destes cursos questões relacionadas à produção limpa, ciclo de vida do produto, ecoeficiência, ecodesign e sistemas de certificação, enquanto embasamento de uma mudança de paradigmas produtivos. Entretanto, considerando-se os objetivos dos programas, nota-se que um número considerável de disciplinas poderia inserir ou aprofundar o 
A sustentabilidade nos projetos pedagógicos no ensino superior: um estudo sobre a engenharia de produção nas universidades públicas do Estado de São Paulo

conceito de sustentabilidade em suas ementas. Além disso, o uso generalizado do conceito e o seu isolamento na estrutura curricular podem apontar sua inserção apenas como um requisito formal dos projetos pedagógicos.

A proposta pedagógica de um curso de graduação expressa uma visão sobre diferentes temas que depende, por sua vez, das características da área de atuação profissional e da realidade institucional. Certamente, as dimensões da sustentabilidade abordadas nos projetos pedagógicos são influenciadas pela área de conhecimento e pela instituição, embora essa influência não deva atuar como impeditivo ao processo crítico que permite rever e ampliar o significado atribuído ao conceito de sustentabilidade, sobretudo, quando se assume que quanto mais técnica e especializada é a abordagem em torno da sustentabilidade, menos politizado e transformador será o debate.

\section{Referências}

ABRAMOVAY, Ricardo. Desigualdades e limites deveriam estar no centro da Rio +20. Revista do Instituto de Estudos Avançados da USP, São Paulo, v. 26, n. 74, p. 21-33, jan./abr. 2012.

ANDRADE, Daniel Caixeta; ROMEIRO, Ademar. Capital natural, serviços ecossistêmicos e sistema econômico: rumo a uma "Economia dos Ecossistemas". Texto para discussão IE/Unicamp, n. 159, p. 1-23, 2009.

ALMEIDA, Luciana Togeiro de. Economia verde: a reiteração de ideias à espera de ações. Revista do Instituto de Estudos Avançados da USP, São Paulo, v. 26, n. 74, p. 93-104, 2012.

ASSOCIAÇÃO BRASILEIRA DE ENGENHARIA DE PRODUÇÃO (ABEPRO). Áreas e subáreas da engenharia de produção. Disponível em: <http://www.abepro.org.br/ interna. $a s p ? p=399 \& m=424 \& s s=1 \& c=362>$. Acesso em: out. 2013.

BARBOSA, Samara Wanderley Xavier. A significação do projeto político pedagógico: um olhar avaliativo. Espaço do Currículo, UFPB, João Pessoa, v. 4, n. 2, p. 227-39, mar. 2012.

BRASIL. Ministério da Educação e Cultura. Resolução CNE/CES n 11/2002, de 11 de março de 2002. Institui diretrizes curriculares nacionais dos cursos de engenharia. Brasília, 2002.

CAÇÃO, Maria Izaura. Proposta curricular do Estado de São Paulo: retorno do discurso regulativo da tylerização na educação pública. Espaço do Currículo, UFPB, João Pessoa, v. 13, n. 1, p. 380-94, mar./set. 2010.

COMISSÃO MUNDIAL SOBRE MEIO AMBIENTE E DESENVOLVIMENTO

(CMMAD). Nosso Futuro Comum. Rio de Janeiro: Fundação Getúlio Vargas, 1988.

COORDENAÇÃO DE APERFEIÇOAMENTO DE PESSOAL DE NÍVEL SUPERIOR

(CAPES). Relação de cursos recomendados e reconhecidos. Disponível em: 
<http://conteudoweb.capes.gov.br/conteudoweb/ProjetoRelacaoCursosServlet?acao=pesquisa rArea\&codigoGrandeArea=30000009\&descricaoGrandeArea=ENGENHARIAS+> . Acesso em: out. 2013.

CAVALCANTI, Clovis. Sustentabilidade: mantra ou escolha moral? Uma abordagem ecológico-econômica. Revista do Instituto de Estudos Avançados da USP, São Paulo, v. 26, n. 74, p. 35-50, 2012.

CECHIN, Andrei; PACINI, Henrique. Economia Verde: por que o otimismo deve estar aliado ao ceticismo da razão. Revista do Instituto de Estudos Avançados da USP, São Paulo, v. 26, n. 74, p. 121-135, 2012.

DIAS, Reinaldo. Gestão ambiental: responsabilidade social e sustentabilidade. São Paulo: Atlas, 2008.

FLEURY, Afonso. O que é engenharia de produção? In: BATALHA, Mário Otávio (Org.). Introdução à engenharia de produção. Rio de Janeiro: Elsevier, 2008, p. 1-10.

FUKS, Mauricio. Reflexões sobre o paradigma da economia ecológica para a gestão ambiental. Revista do Instituto de Estudos Avançados da USP, São Paulo, v. 26, n. 74, p. 105-118, 2012.

GADOTTI, Moacir. Educar para a Sustentabilidade. Inclusão Social, Brasília, v. 3, n. 1, p 75-78, out. 2007/mar. 2008.

HEIN, Nelson; KROENKE, Adriana; ROCHA, Irani. Percepção ambiental dos graduandos em engenharia de produção em uma universidade do Vale do Itajaí-SC. Tecno-Lógica, Santa Cruz do Sul, v. 13, n. 2, p. 70-74, jul./dez. 2009.

LEFF, Enrique. Saber ambiental: sustentabilidade, racionalidade, complexidade, poder. Petrópolis: Vozes, 2001.

MATTOS, Luciano; HERCOWITZ, Marcelo (Orgs.). Economia do meio ambiente e serviços ambientais: estudo aplicado à agricultura familiar, às populações tradicionais e aos povos indígenas. Brasília: Embrapa Informação Tecnológica, 2011.

NASCIMENTO, Elimar Pinheiro do. Trajetória da sustentabilidade: do ambiental ao social, do social ao econômico. Revista do Instituto de Estudos Avançados da USP, São Paulo, v. 26, n. 74, p.51-64, 2012.

QUELHAS, Osvaldo Luiz Gonçalves; ALLEDI FILHO, Cid; MEIRIÑO, Marcelo Jasmin. Responsabilidade social, ética e sustentabilidade na Engenharia de Produção. In: BATALHA, Mário Otávio (Org.). Introdução à engenharia de produção. Rio de Janeiro: Elsevier, 2008, p. 273-303.

ROMEIRO, Ademar. Desenvolvimento sustentável: uma perspectiva econômico-ecológica. Revista do Instituto de Estudos Avançados da USP, São Paulo, v. 26, n. 74, p. 65-92, 2012.

SACHS, Ignacy. Caminhos para o desenvolvimento sustentável. Rio de Janeiro: Garamond, 2002.

SACHS, Ignacy. De volta à mão visível: os desafios da Segunda Cúpula da Terra no Rio de Janeiro. Revista do Instituto de Estudos Avançados da USP, São Paulo, v. 26, n. 74, p. 7 20, 2012. 
A sustentabilidade nos projetos pedagógicos no ensino superior: um estudo sobre a engenharia de produção nas universidades públicas do Estado de São Paulo

SACRISTÁN, José Gimeno. O currículo: uma reflexão sobre a prática. 3. ed. Porto Alegre: Artmed, 2000.

SANTOS, Fernando César Almada. Potencialidades de mudanças na graduação em Engenharia de Produção geradas pelas diretrizes curriculares. Revista Produção, Rio de Janeiro, v. 13, n. 1, p. 26-39, jan. 2003.

SANTOS, Fernando Cesar Almada. Evolução dos cursos de Engenharia de Produção no Brasil. In: BATALHA, Mário Otávio (Org.). Introdução à engenharia de produção. Rio de Janeiro: Elsevier, 2008.

SELIG, Paulo Maurício; CAMPOS, Lúcia Maria de Souza; LERIPIO, Alexandre de Avila. Gestão Ambiental. In: BATALHA, Mário Otávio (Org.). Introdução à engenharia de produção. Rio de Janeiro: Elsevier, 2008, p. 249-272.

SILVA, Maria Abádia da. Do projeto político pedagógico do Banco Mundial ao projeto político pedagógico da escola pública brasileira. Caderno Cedes, Campinas, v. 23, n. 61, p. 283-301, dez. 2001.

UNIVERSIDADE DE SÃO PAULO. Escola Politécnica. Proposta Pedagógica. 2013. Disponível em: < http://pro.poli.usp.br/graduacao/proposta-pedagogica-2/>. Acesso em: out. 2013.

UNIVERSIDADE DE SÃO PAULO. Renovação do reconhecimento do curso de graduação em engenharia de produção mecânica da Escola de Engenharia de São Carlos - USP. São Carlos, 2001.

UNIVERSIDADE FEDERAL DE SÃO CARLOS. Projeto pedagógico do curso de graduação em engenharia de produção da UFSCar, campus São Carlos. São Carlos, 2009.

VASCONCELLOS, Celso dos Santos. Planejamento: projeto de ensino-aprendizagem e projeto político-pedagógico. 22. ed. São Paulo: Libertad, 2012.

VEIGA, Ilma Passos Alencastro. Inovações e Projeto Político Pedagógico: uma relação regulatória ou emancipatória? Caderno Cedes, Campinas, v. 23, n. 61, p. 267-81, dez. 2003.

VEIGA, Ilma Passos Alencastro. Perspectivas para reflexão em torno do projeto político pedagógico. In: VEIGA, Ilma Passos Alencatro; RESENDE, Lúcia Maria Gonçalves de (Orgs.). Escola: espaço do projeto político pedagógico. 17. ed. Campinas: Papirus, 2011, p. 932.

VIEIRA JUNIOR, Milton; FARIA, Adriana Ferreira de. Competências, formação e exercício profissional à luz do Projeto Pedagógico. In: OLIVEIRA, Antônio Carlos (Org.). Tópicos emergentes e desafios metodológicos em engenharia de produção: casos, experiência e proposições. Rio de Janeiro: ABEPRO, 2008. 
Tiago Juliano; Ismail Barra Nova de Melo; Silvio César Moral Marques

Tiago Juliano - Universidade Federal de São Carlos Sorocaba | SP | Brasil. Contato: t.juliano@yahoo.com.br

Ismail Barra Nova de Melo - Universidade Federal de São Carlos Sorocaba | SP | Brasil. Contato: ismail @ufscar.br

Silvio César Moral Marques - Universidade Federal de São Carlos Sorocaba | SP | Brasil. Contato: silviocmm@ufscar.br

Artigo recebido em 8 de outubro de 2015 e aprovado em 10 de outubro de 2016. 